\title{
The Factors of Selecting Malaysia as Tourist Destination
}

\author{
A S A Ferdous Alam \\ Universiti Kebangsaan Malaysia, Bangi, Malaysia \\ Email: ferdous@ukm.edu.my
}

ErAC

Universiti Kebangsaan Malaysia, Bangi, Malaysia

Halima Begum

Universiti Kebangsaan Malaysia, Bangi, Malaysia

Md Mahmudul Alam

Universiti Utara Malaysia, Kedah, Malaysia

\section{Doi:10.5901/mjss.2015.v6n3s1p491}

\section{Abstract}

Tourism is an emerging economic sector for Malaysia. The purpose of this study is an attempt to understand the factors that attract tourists to visit Melaka State of Malaysia. The primary data were collected through questionnaire survey on 735 tourists who visited the state of Melaka, Malaysia. This study used descriptive statistics, confirmatory factor analysis, and structural equation modelling (SEM) in order to analyze and draw the inferences. Model fit was initially tested using the overall fit and regression paths. Then the hypothesized model was analysed and modified based on the results of the analysis to find a better fit of the data and to more adequately describe the relationships between the factors. The study found that several economic, environmental, cultural and community factors have positive significant influence in attracting tourists to Melaka.

Keywords: Tourist attraction; structural equation modelling (SEM); Malaysia

\section{Introduction}

Tourism refers to travelling to relatively uninterrupted or uncontaminated natural areas with focus on learning, appreciating and enjoying the scenery and its wild flora and fauna, as well as other existing cultural and historical aspects. These include places of archaeological and historical importance, religious sites, sanctuaries, parks, hill resorts and clubs and sea beaches, and many others. This is a multi-sector industry consisting of a collection of activities, services and industries that delivers travel experience, as well as transportation, accommodation, eating and drinking businesses, retail shops, entertainment businesses, activities, facilities and other hospitality services offered for individuals or groups travelling away from home (Bhargava, 2009).

As a development strategy, the tourism sector has achieved significant earnings and provided substantial contribution to the local and national economy for many countries. It is also identified as one of the largest and fastest growing industries (Miller, 1990; Hunter, 1995 and McMinn, 1997). For some developed or developing countries, the tourism industry forms a critical component of the local, regional and national economy, contributing significantly to employment opportunities, GDP growth and foreign exchange earnings. Not merely for developing countries, tourism has turned out to be one of the very important sources of earnings for the developed countries where it has already created substantial foundation for tourism based economy, for example in countries like Singapore, Maldives and Malaysia of which the total contribution of Travel \& Tourism to GDP in 2011 is $8.2 \%, 70.5 \%, 15 \%$ respectively. This study, try to understand the factors that attract tourists to visit Melaka State of Malaysia. 


\section{Literature Review}

In the case of Malaysia, tourism is the fifth leading industry after Oil, Gas and Energy, Financial Services, Wholesale and Retail, and Palm oil (Jabatan Perdana Menteri, 2010). Today, the tourism industry of Malaysia has moved with such rapidity to become the second income generator to the national economy whilst experiencing tremendous growth year by year. The total contribution of travel and tourism to GDP was 15.8\% in 2013 (WTTC, 2013). Even though the tourism industry is a latecomer in Malaysia compared to its neighbouring countries, namely Thailand and Singapore, it has recorded a successful performance in terms of tourist arrivals and receipts (Tourism Malaysia, 2011). For example, in 2010, Malaysia recorded 24.5 million tourist arrivals and RM55.6 billion in tourist receipts compared to 5.5 million tourist arrivals and RM8.5 billion in tourist receipts in 1998 (Mintel, 2011). Globally, Malaysia ranked 9th out of the ten top most visited countries in terms of international tourist arrivals in 2009 and 2010, achieving figures of 23.6 and 24.6 million tourist arrivals respectively (United Nation, 2007 and World Tourism Organization, 2011).

Lying just north of the equator, Malaysia is located south of Cambodia and Vietnam and north of Singapore and Indonesia. More than one thousand islands are part of Malaysia with some 38 designated as marine parks. Parts of the primeval rainforest are more than 100 million years old with a dazzling selection of birds and wildlife. Malaysia has wonderful golden beaches, lush vegetation, mountains, and fabulous shopping centres which are associated with some magnificent hotels. This has made the country the fastest growing destination in South East Asia. The mix of the ancient and the ultra-modern makes Malaysia a fascinating place to visit, while the low cost of living and huge selection of choices for visitors make it an ideal holiday location. Malaysia experiences tropical climate throughout the year, enjoying warm days and mild evenings in all seasons. The country also offers a fascinating cultural mix with colourful festivals, unique arts and crafts, architecture, food and a rich array of dance forms. It is ideally placed to take advantage of its increased interest in the tourism industry, especially the ecotourism segment, as it possesses a wide variety of natural land and marine habitats. Therefore, the long term prospects of Malaysian tourism remain optimistic as a result of a strong government support and a relatively strong and stable political situation (Malaysia Tourism Report, 2010).

Admittedly, according to Bhuiyan et al. (2013), foreign tourists' arrival and tourist expenditure on the basis of per capita and per diem is increasing year by year in Malaysia. Malaysia has targeted to capture a place within the top 10 countries in the world in terms of international tourist arrivals through various development plans. In this regard, less developed countries (LDCs) consider tourism as an important tool for their economic development (Taleghani, 2010).

It is to be hoped that every nation makes some effort to conserve and maintain their cultural resources. In Malaysia, although a special law to protect and preserve historic premises has been in existence since 1957 (Abdul Rahman, 1986), the subject of cultural conservation has become a focus for public concern only over the past few years.

In the tourism industry, achieving competitive advantage refers to the notion where a destination must have an overall "appeal" and where the tourist experience offered is superior to that of the alternative destinations competing for the same target tourists (Dwyer and Kim, 2003). This study, therefore, is an attempt to understand the factors that attract tourists to visit Malaysia and consider it as a tourist destination.

\section{Data and Methodology}

The study used primary data that were collected from Melaka State of Malaysia. Melaka was selected because it is one of the top-picked holiday getaways for its natural, cultural, and historical heritage which was declared a UNESCO World Heritage site in 2008. Melaka has improved their products in and about the state, namely the convenience of their transportation hub i.e. by upgrading the central bus terminal (Melaka Central), the UNESCO Heritage Zones, the revitalized Melaka River, the night zoo, in-house guides in the museum and many other places of historical and cultural interests, as well as good local dining and comfortable accommodation. Most of the tourist attractions are concentrated in its small city centre, which encompasses Jonker Walk that houses Melaka's traditional Chinatown and exhibits Peranakan architecture. Additionally, A Famosa Fort and St. Paul Hill are among the tourist attractions located in the Bandar Hilir, which is the old city area. There are also many shopping centres located nearby, including the Melaka Straits Mosque which is also located in this area. There are also numerous islands near Melaka including Pulau Upeh near Klebang Beach and Pulau Besar. According to Tourism Malaysia (2011), a total of 12.35 million tourists had arrived in Melaka in 2011.

Sustainability has become an important topic and concept in relation to tourism planning and development (Inskeep, 1991; Southgate \& Sharpley, 2002 and Yuksel et. al., 1999). To determine the sustainability of tourism attractions, the economic, environmental, cultural and community aspects were considered in this study. To attract tourists, the local economic factors like currency exchange facility, shopping facility, overall economic condition of the 
locality and many other related factors are important. Among the environmental factors, aspects such as good management, landscaping, proper sanitation, sustainability of ecosystems and several other factors were the focus of this study. In terms of the cultural perspective of tourism, the diversity of traditions and culture, tourism activities, existing tradition and culture, handicrafts market, racial diversity, different cuisines and many other related factors were considered. Finally, the factors of community-inspired support of tourism like infrastructure, convenience of communication, informative community, high speed internet facility, and development of local community and a few other factors were those considered for the measurement of sustainable tourism.

The data of the study were collected from a questionnaire survey on 735 tourists. The non-probability convenience sampling technique was used for selecting samples. The survey was carried out from October to November 2013.

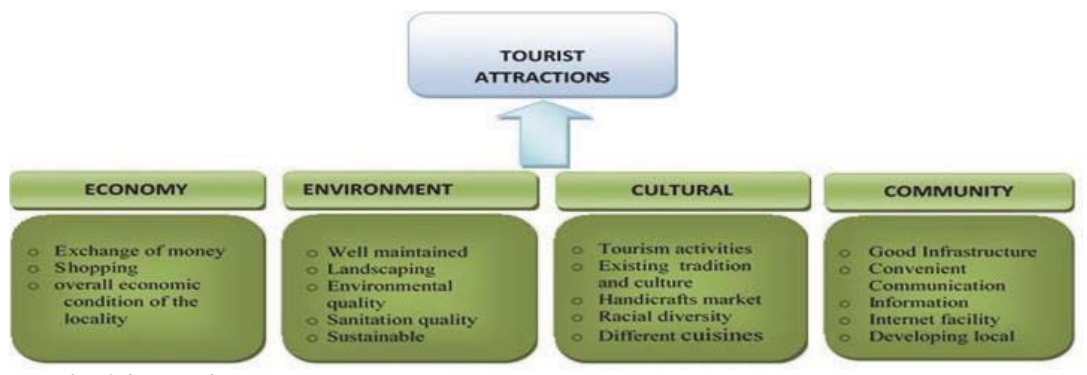

Figure 1. Framework of the study

Source: Authors' analysis on primary survey from Melaka 2013

This study used descriptive statistics, confirmatory factor analysis, and structural equation modelling (SEM) to analyze and draw the inferences. The SEM model was tested by using AMOS. Model fit was initially tested using the overall fit and regression paths. Then the hypothesized model was analysed and modified based on the results of the analysis to find a better fit of the data and to more adequately describe the relationships between the factors.

\section{Findings and Discussion}

\subsection{Demographic profile of the respondents}

There is no difference in terms of gender and marital status among the respondents (Table 1). In terms of age range, most of the respondents are categorized within the 21 to 30 years age group followed by the 31 to 40 years age group. Around $75 \%$ of the tourists are Malaysian; most of them came from Melaka that is about $17 \%$ while others came from Selangor (12.38\%), Kuala Lumpur (10.48\%), Johor Baru (8.57\%), Negeri Sembilan (4.22\%), Kelantan (4.22\%), Kedah (3.53\%), Pulau Pinang (3.4\%), Perak (2.86\%), Sabah (2.58\%), Terengganu (2.04\%), Pahang (1.49\%), Sarawak (1.22\%), Perlis $(0.68 \%)$ and others $(7.76 \%)$.

Most of the respondents are also from the Malay ethnic group and their religion is Islam. The majority of the respondents are self-employed, namely at almost $35.24 \%$. Around $62 \%$ of them are highly educated, in that they reported being a diploma holder or a graduate. Around $33.47 \%$ of the families comprise of $3-4$ members while around $28 \%$ of the families consist of 5-6 people. The income of most of the respondents are below RM 1000 (around USD \$300). Among the respondents, $50 \%$ stay for at least one night at the place they are visiting in Melaka.

Table 1. Demographic profile of the respondents

\begin{tabular}{|c|c|c|c|c|c|}
\hline Gender & Male (51.16) & Female (48.84) & & & \\
\hline Age & $11-20(13.33)$ & $21-30(40.54)$ & $31-40(26.67)$ & $41-50(12.65)$ & $50-<(6.81)$ \\
\hline Ethnicity & Malay (58.64) & Indian (7.21) & Chinese (14.69) & Others (19.46) & \\
\hline Religion & Islam (64.9) & Hindu (7.21) & Buddha (10.61) & Christian (14.42) & Others (2.86) \\
\hline Marital Status & Married (48.16) & Single (48.16) & Single Mothers (2.45) & Single Fathers (0.68) & Others $(0.55)$ \\
\hline Occupation & Self Employed (35.24) & Government (25.85) & Private (26.94) & Others (11.97) & \\
\hline Income (RM/ monthly) & Below 1000 (42.04) & $1001-1500(8.57)$ & $1501-2000(14.42)$ & $2001-2500(6.8)$ & $2500+(28.16)$ \\
\hline Education & Diploma/Degree (61.91) & Primary school (14.15) & High school (20.68) & Not in school (1.22) & Others $(2.04)$ \\
\hline Nationality & International (17.41) & Malaysian (74.83) & Others (7.78) & & \\
\hline Number of Households & Below 2 (24.22) & 3-4 (33.47) & $5-6(27.76)$ & $7(8.44)$ & $8<(6.11)$ \\
\hline Type of visit & Local (19.32) & Visitors (29.93) & Tourist* $(50.48)$ & Others $(0.27)$ & \\
\hline
\end{tabular}

Note: * Who stayed at least 1 night treated as tourist and rest are visitors;

Percentage are given in the parenthesis 


\subsection{Structural Equation Model (SEM)}

The SEM model was used to examine the hypothesized relationships between the constructs (factors) in the model (Figure 2). The findings of the study indicate that there are positive significant relationship between tourist attraction and its economic, environmental, cultural and community factors. Among the latent variables, the Structural Equation model shows that the environmental construct has the highest influence (0.92) on tourist attraction compared to cultural (0.85), economic (0.81), and community $(0.80)$ constructs.

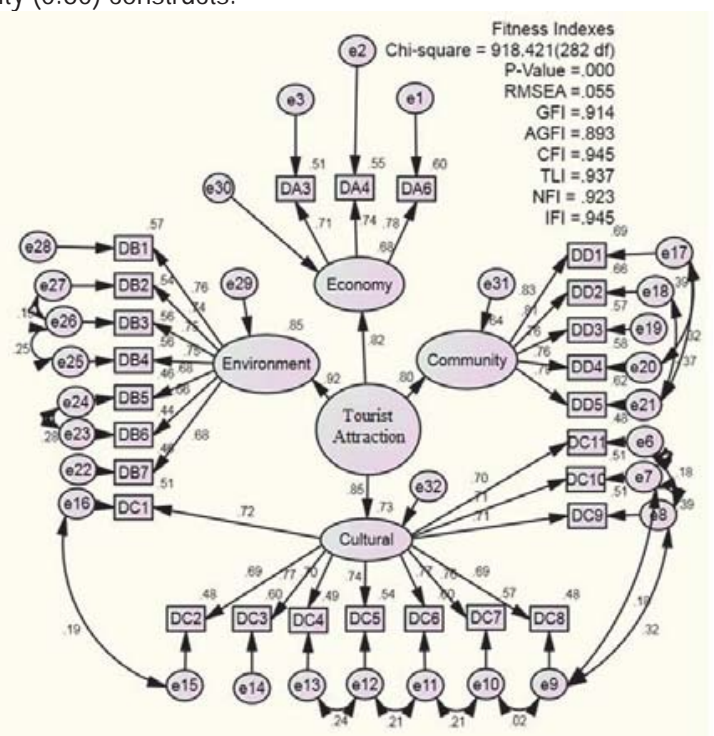

Figure 2. Structural Equation Model diagram for measuring tourist attraction in Melaka

Convergent validity test results included variance estimates between factors and variable loadings on factors for each variable (Table 2). Among the economic latent variables, the path coefficient of overall economic condition of the locality (DA6) obtained the highest value (0.78), followed by tourist shopping facility (DA4), and money exchange facility (DA3).

Among several latent variables of environment factors, well maintained heritage (DB1) obtained the highest path coefficient, followed by environmental quality (DB3), well protected heritage (DB4), Melaka's landscape (DB2), sanitation quality (DB5), seasonality (DB6) and sustainability of ecosystems (DB7) (Table 2). The path coefficient of tourism activities (DC3) and handicrafts market (DC6) attained the highest position among the cultural latent variables, followed by racial diversity (DC7), diversity in tradition and culture (DC5), traditions and cultures (DC1), scope of learning (DC9), meeting opportunities with the community (DC10), food diversity (DC11), multi-ethnic society (DC8), and friendly community (DC2) (Table 2).

Table 2. Output summary of the structural equation model

\begin{tabular}{|c|c|c|c|c|c|}
\hline $\begin{array}{c}\text { Latent } \\
\text { Variables }\end{array}$ & Observed Variables & $\begin{array}{c}\text { Correlation } \\
\text { (Coefficient) }\end{array}$ & $\begin{array}{c}\text { Effect } \\
\text { (Variance) }\end{array}$ & $\begin{array}{c}\text { Correlation } \\
\text { (Coefficient) }\end{array}$ & Effect (Variance) \\
\hline \multirow{3}{*}{ Economy } & \multirow{3}{*}{$\begin{array}{l}\text { Money exchange facility (DA3) } \\
\text { Tourist shopping facility (DA4) } \\
\text { Overall economic condition of the } \\
\text { locality (DA6) }\end{array}$} & 0.71 & 0.51 & \multirow{3}{*}{0.82} & \multirow{3}{*}{0.68} \\
\hline & & 0.74 & 0.55 & & \\
\hline & & 0.78 & 0.60 & & \\
\hline \multirow{7}{*}{ Environment } & Well maintenance (DB1) & 0.76 & 0.57 & \multirow{7}{*}{0.92} & \multirow{7}{*}{0.85} \\
\hline & \multirow{6}{*}{$\begin{array}{l}\text { Melaka landscape (DB2) } \\
\text { Environmental quality (DB3) } \\
\text { Well protected of heritage (DB4) } \\
\text { Sanitation quality (DB5) } \\
\text { Seasonality (DB6) } \\
\text { Sustainability of ecosystems (DB7) }\end{array}$} & 0.74 & 0.54 & & \\
\hline & & 0.75 & 0.56 & & \\
\hline & & 0.75 & 0.56 & & \\
\hline & & 0.68 & 0.46 & & \\
\hline & & 0.68 & 0.44 & & \\
\hline & & 0.68 & 0.46 & & \\
\hline
\end{tabular}




\begin{tabular}{|c|c|c|c|c|c|}
\hline \multirow{11}{*}{ Cultural } & \multirow{11}{*}{\begin{tabular}{|l} 
Traditions and cultures (DC1) \\
Friendly community (DC2) \\
Tourism activities (DC3) \\
Prevalent practice (DC4) \\
Diversity in tradition and culture (DC5) \\
Handicrafts market (DC6) \\
Racial diversity (DC7) \\
Multi-ethnic society (DC8) \\
Scope of learning (DC9) \\
Meeting scope with community (DC10) \\
Food diversity (DC11)
\end{tabular}} & 0.72 & 0.51 & \multirow{11}{*}{0.85} & \multirow{11}{*}{0.73} \\
\hline & & 0.69 & 0.47 & & \\
\hline & & 0.77 & 0.60 & & \\
\hline & & 0.70 & 0.49 & & \\
\hline & & 0.74 & 0.54 & & \\
\hline & & 0.77 & 0.60 & & \\
\hline & & 0.76 & 0.57 & & \\
\hline & & 0.69 & 0.48 & & \\
\hline & & 0.71 & 0.51 & & \\
\hline & & 0.71 & 0.51 & & \\
\hline & & 0.69 & 0.48 & & \\
\hline & Good infrastructural facility (DD1) & 0.83 & 0.68 & & \\
\hline & Convenient communication (DD2) & 0.81 & 0.65 & & \\
\hline Community & Information accessibility (DD3) & 0.76 & 0.57 & 0.80 & 0.64 \\
\hline & Internet network facility (DD4) & 0.76 & 0.58 & & \\
\hline & Local community supports (DD5) & 0.79 & 0.62 & & \\
\hline
\end{tabular}

Note: The path coefficient $>0.6$ consider significant

The availability of adequate money exchange facilities is a factor that attracts tourists to Melaka as mentioned by $68.57 \%$ of respondents (Table 3). This is followed by the attractive facilities for shopping and availability of gift and souvenir shops which have attracted tourists to come to this place as mentioned by $67.62 \%$ of the respondents. Overall, the economic condition and its growing nature were mentioned by $68.03 \%$ of the respondents as another factor that attracts tourists to Melaka.

Table 3. Economic factors of tourist attraction in Melaka

\begin{tabular}{|c|c|c|c|c|c|c|c|}
\hline Economic Issues & 1 & 2 & 3 & 4 & 5 & Mean & SD \\
\hline Money exchange facility & $2(0.27)$ & $24(3.27)$ & $205(27.89)$ & $344(46.80)$ & $160(21.77)$ & 3.87 & 0.8 \\
\hline Tour & 30.4 & $32(4.35)$ & $203(27$ & $331(45$. & $166(22$. & 3.8 & 0.83 \\
\hline Overall economic condition & $8(1.09)$ & $14(1.90)$ & $213(28.98)$ & $345(46.94)$ & 155 (21.09) & 3.85 & 0.81 \\
\hline
\end{tabular}

Note: 1=Very Unsatisfied; 2= Unsatisfied; 3= Neutral, 4=Satisfied; 5= Very Satisfied,

Percentage are in the parenthesis

Around $72.38 \%$ of the respondents were very satisfied and satisfied about the well maintained of the heritage sites in Melaka (Table 4). Furthermore, $65.71 \%$ of the respondents mentioned their satisfaction with the quality of sanitation and hygiene facilities available in the city. The beauty of Melaka's landscape and the well-protected ecological heritage site were selected by $70.75 \%$ and $70.88 \%$ of the respondents respectively. The eco-friendly environment and the good practices in the sustainability of the eco-system which have contributed to tourists being attracted to visit Melaka were mentioned by $69.66 \%$ and $70.2 \%$ of the respondents respectively. However, most of the visitors, namely around $63.95 \%$, reported that they came based on the seasonality of the weather.

Table 4. Environment factors of tourist attraction in Melaka

\begin{tabular}{|lccccccc|}
\hline Environmental Issues & $\mathbf{1}$ & $\mathbf{2}$ & $\mathbf{3}$ & $\mathbf{4}$ & $\mathbf{5}$ & Mean & SD \\
\hline Well maintenance & $2(0.27)$ & $19(2.59)$ & $182(24.76)$ & $388(52.79)$ & $144(19.59)$ & 3.88 & 0.75 \\
Melaka landscape & $2(0.27)$ & $20(2.72)$ & $193(26.26)$ & $344(46.80)$ & $176(23.95)$ & 3.91 & 0.79 \\
Environmental quality & $4(0.54)$ & $24(3.27)$ & $195(26.53)$ & $372(50.61)$ & $140(19.05)$ & 3.87 & 0.78 \\
Well protected of heritage & $2(0.27)$ & $23(3.13)$ & $189(25.71)$ & $360(48.98)$ & $161(21.90)$ & 3.89 & 0.78 \\
Sanitation quality & $4(0.54)$ & $34(4.63)$ & $214(29.12)$ & $336(45.71)$ & $147(20)$ & 3.82 & 0.8 \\
Seasonality & $2(0.27)$ & $23(3.13)$ & $240(32.65)$ & $335(45.58)$ & $135(18.37)$ & 3.79 & 0.78 \\
Sustainability of ecosystems & $4(0.54)$ & $22(2.99)$ & $193(26.26)$ & $339(46.12)$ & $177(24.08)$ & 3.9 & 0.81 \\
\hline
\end{tabular}

Note: 1=Very Unsatisfied; 2= Unsatisfied; 3= Neutral, 4=Satisfied; 5= Very Satisfied

Percentage are in the parenthesis

The visitors also reported feeling proud and pleased to visit Melaka to experience the traditions and the cultural diversity, and this was mentioned by $77.01 \%$ of the respondents (Table 5). Meanwhile, $63.39 \%$ of the respondents mentioned that 
the local community is friendly and their manners and hospitality are satisfactory. According to $73.88 \%$ of the respondents, they were very satisfied and satisfied with the current arts and cultural scene of Melaka city. Therefore, the heritage of Baba and Nyonya which is still practiced including the use of Baba and Nyonya attire was mentioned by $65.30 \%$ of the respondents. Among the respondents, $48.16 \%$ mentioned that the existing tradition and culture in Melaka was satisfactory. Visitors also expressed their satisfaction at seeing several artistic designs of handicrafts that are eyecatching, as mentioned by $52.38 \%$ of the respondents.

Racial diversity and ethnic diversity that coexist in harmony are also the factors that attracted visitors as mentioned by $68.71 \%$ and $62.3 \%$ of the respondents respectively. $65.04 \%$ of the respondents opined that there is opportunities to meet with the local community in Melaka. Additionally, such opportunities also help them to gain knowledge about the multiracial and multicultural society in Malaysia, as mentioned by $48.84 \%$ of the respondents. There is also the diversity of food such as Indian, Baba and Nyonya, Chinese, and Malay food, and many others that have attracted tourists to visit Melaka, as indicated by $66.66 \%$ of the respondents.

Table 5. Cultural factors of tourist attraction in Melaka

\begin{tabular}{|lccccccc|}
\hline Cultural Issues & $\mathbf{1}$ & $\mathbf{2}$ & $\mathbf{3}$ & $\mathbf{4}$ & $\mathbf{5}$ & Mean & SD \\
\hline Traditions and cultures & $2(0.27)$ & $13(1.77)$ & $154(20.95)$ & $366(49.80)$ & $200(27.21)$ & 4.02 & 0.76 \\
Friendly community & $2(0.27)$ & $19(2.59)$ & $204(27.76)$ & $362(49.25)$ & $148(20.14)$ & 3.86 & 0.77 \\
Tourism activities & $3(0.41)$ & $21(2.86)$ & $168(22.86)$ & $378(51.43)$ & $165(22.45)$ & 3.93 & 0.77 \\
Prevalent practice & $8(1.09)$ & $25(3.40)$ & $222(30.20)$ & $326(44.35)$ & $154(20.95)$ & 3.81 & 0.84 \\
Diversity in tradition and culture & $3(0.41)$ & $32(4.35)$ & $190(25.85)$ & $354(48.16)$ & $156(21.22)$ & 3.85 & 0.81 \\
Handicrafts market & $4(0.54)$ & $28(3.81)$ & $161(21.90)$ & $385(52.38)$ & $157(21.36)$ & 3.9 & 0.79 \\
Racial diversity & $3(0.41)$ & $18(2.45)$ & $209(28.44)$ & $330(44.90)$ & $175(23.81)$ & 3.89 & 0.80 \\
Multi-ethnic society & $6(0.82)$ & $35(4.76)$ & $236(32.1)$ & $321(43.7)$ & $137(18.6)$ & 3.75 & 0.84 \\
Scope of learning & $6(0.82)$ & $18(2.45)$ & $221(30.07)$ & $359(48.84)$ & $131(17.82)$ & 3.80 & 0.78 \\
Meeting scope with community & $6(0.82)$ & $25(3.40)$ & $226(30.74)$ & $330(44.90)$ & $148(20.14)$ & 3.8 & 0.82 \\
Food diversity & $5(0.68)$ & $33(4.49)$ & $239(32.52)$ & $313(42.59)$ & $145(19.73)$ & 3.86 & 0.74 \\
\hline
\end{tabular}

Note: 1=Very Unsatisfied; $2=$ Unsatisfied; $3=$ Neutral, 4=Satisfied; $5=$ Very Satisfied

Percentage are in the parenthesis

Finally, among the community latent variables, the path coefficient of good infrastructural facility (DD1) is the highest, followed by the convenience of communication (DD2), local community support (DD5), information accessibility (DD3), and internet network facility (DD4) (Table 2). The infrastructural facility of Melaka is satisfactory as mentioned by $69.53 \%$ of the respondents (Table 6). According to $58.78 \%$ of the respondents, the facility of internet access is good. At the same time, the information from local people is also easily accessible as mentioned by $60.28 \%$ of the respondents. The local community is also very supportive and this was mentioned by $64.08 \%$ of the respondents. Therefore, the convenience of overall communication in Melaka has attracted tourists to visit Melaka as mentioned by $62.31 \%$ of the respondents.

Table 6. Community factors of tourist attraction in Melaka

\begin{tabular}{|lccccccc|}
\hline Community Issues & $\mathbf{1}$ & $\mathbf{2}$ & $\mathbf{3}$ & $\mathbf{4}$ & $\mathbf{5}$ & Mean & SD \\
\hline Good Infrastructural facility & $1(0.14)$ & $17(2.31)$ & $206(28.03)$ & $376(51.16)$ & $135(18.37)$ & 3.85 & 0.74 \\
Convenient Communication & $3(0.41)$ & $34(4.63)$ & $240(32.65)$ & $344(46.80)$ & $114(15.51)$ & 3.72 & 0.79 \\
Information accessibility & $5(0.68)$ & $39(5.31)$ & $248(33.74)$ & $338(45.99)$ & $105(14.29)$ & 3.68 & 0.81 \\
Internet network facility & $10(1.36)$ & $50(6.80)$ & $243(33.06)$ & $322(43.81)$ & $110(14.97)$ & 3.64 & 0.86 \\
Local community supports & $7(0.95)$ & $31(4.22)$ & $226(30.75)$ & $355(48.30)$ & $116(15.78)$ & 3.73 & 0.8 \\
\hline
\end{tabular}

Note: 1=Very Unsatisfied; $2=$ Unsatisfied; $3=$ Neutral, 4=Satisfied; 5= Very Satisfied

Percentage are in the parenthesis

\subsection{Diagnostic Tests of SEM}

To determine the model's goodness of fit, several types of indicators and conditions were tested and these are given in Table 7. The Chi-square value is significant at $1 \%$ level $(p<0.00)$ which is 3.26 with 282 degree of freedom $=918.42$. The goodness of fit index (GFI) and the normed fit index (NFI) are above 0.90, indicating a good fit (Bentler and Bonett, 1990). The model has a GFI of 0.91 and a NFI of 0.92 , which show a good fit model. The adjusted goodness of fit (AGFI) is 0.89 , which is a little bit less than the acceptable good fit. However, the comparative fit index (CFI) which is 0.95 represents a 
reasonable model fit (Sim et al., 2006). The root-mean square error of approximation (RMSEA) shows the proportion of the variance of the model is 0.05 , indicating a reasonable model fit (Sim et al., 2006). Overall, the GFI, AGFI, NFI, NNFI, $\mathrm{CFI}$, and RMSR tests confirm the reliability of this path measurement model.

Table 7. Fit indices of structural equation model

\begin{tabular}{|lcc|}
\hline Goodness of fit measure & Categorical data Value & General rule for acceptable fit \\
\hline Chi-square value (X2) & 918.42 & \\
Degree of freedom (df) & 282 & Ratio of X2 to df $\leq 2$ or 3 \\
Chi-square (X2)/df & 3.26 & $<.08$ \\
Root mean square error of approximation (RMSEA) & 0.05 & $\leq .08$ \\
Root Mean Square Residual (RMR) & 0.03 & $\geq .90$ \\
Tucker-Lewis index (TLI) & 0.94 & $\geq .90$ \\
Normed Fit Index (NFI) & 0.92 & $\geq .90$ \\
Incremental fit index (IFI) & 0.95 & $\geq .90$ \\
Comparative fit index (CFI) & 0.95 & $\geq .90$ \\
Goodness of fit index (GFI) & 0.91 & $\geq .90$ \\
Adjusted goodness of fit index (AGFI) & 0.89 & \\
\hline
\end{tabular}

Cronbach's alpha is used to determine the reliability of multi-item factors. The latent variables in this model have high Cronbach's Alpha values which are at $0.795,0.886,0.927$ and 0.872 for economy, environment, culture, and community, respectively. Therefore, the reliability level for attitudes towards economy, environment, culture and community all meet the critical value of 0.7 as suggested by Nunnally and Bernstein (1994).

The result of the estimation indicates that the critical ratio (C.R.) value for regression between the economic latent variables and its three observed variables are out of range at +1.96 , which indicates all of the three variables are significant. Similar results were also found for the environmental latent variables with its seven observed variables, the cultural latent variables with its eleven observed variables, and the community latent variables with its five observed variables.

\section{Conclusion and Recommendation}

Tourism is the second largest economic sector in Malaysia. Each year many tourists come and visit the tourist destinations and attractions in Malaysia, and Melaka is one of the major tourist destinations among the many tourist spots in Malaysia. This study found that several factors from the economic, environmental, cultural and community constructs are important in attracting tourists to Melaka.

Chi and Qu (2008) suggest that tourist satisfaction is considered a necessary goal for a business because satisfied tourists will recommend the place to other people. Therefore, for the improvement of the tourism sector in Malaysia, laws and policies related to tourists should be established in Malaysia. At the same time, public and private sectors need to be involved in developing long term urban planning and development planning. More employment in the local communities needs to be established through development of new tourist industries and restoration work such as development of ecotourism, nature tourism, cultural tourism, service tourism and other potential tourism products. Accordingly, all the necessary training and support should be given to the tour guides to make them more capable of effectively guiding the international tourists coming to this country.

\section{Acknowledgement}

This work was supported by the Fundamental Research Grant Scheme (FRGS/1/2013/SS08/UKM/02) under the leadership of Prof. Dr. Er Ah Choy, Faculty of Social Sciences and Humanities (FSSK), Universiti Kebangsaan Malaysia and Research Development Fund (DPP-2014-179) led by Associate Professor Dr. Sivapalan Selvadurai, Faculty of Social Sciences and Humanities (FSSK), Universiti Kebangsaan Malaysia are gratefully acknowledged.

\section{References}

Bhargava Mohit. (2009). Tourism: Issues and perspectives. New Delhi, India: Raj Publications.

Bhuiyan, M. A. H., Siwar, C., Ismail, S. M., (2013). Tourism Development in Malaysia from the Perspective of Development Plans. Asian 
Social Science, Vol. 9, No. 9; 2013.

Chi, C. G. \& Qu, H. (2008). Examining the structural relationships of destination image, tourist importance-satisfaction analysis by origin of visitor, Journal of Travel Research, 39, 252-260.

Dwyer, L. and Kim, C. (2003). Destination competitiveness: Determinants and Indicators. Current Issues in Tourism, 6(5), 369-414.

Hunter, C. (1995). On the need to re-conceptualise sustainable tourism development. Journal of Sustainable Tourism, 3 (3), $155-65$.

Inskeep, E. (1991). Tourism Planning: An Integrated and Sustainable Development Approach, New York: Van Nostrand Reinhold.

Jabatan Perdana Menteri (2010): Economic Transformation Programme: A Roadmap for Malaysia, Performance Management and Delivery Unit (PEMANDU) 2011, 317.

Malaysia Tourism Report Q3 (2010). Business Monitor International, London, UK, 5.

McMinn, S. (1997). The challenge of sustainable tourism. The Environmentalist,17 (2), 135-141

Miller, M.L. (1990) Tourism in the coastal zone: Portents, problems and possibilities. In M.L. Miller and J. Auyong (eds) Proceedings of the 1990 Congress on Coastal and Marine Tourism Vol. 1 (pp. 1-8). Newport, OR: National Coastal Resources Research and Development Institute.

Mintell (2011). Country report no.2, Asia Pacific May 2011. London: Mintel International Group Ltd.

Nunnally, J. C., \& Bernstein, I. H. (1994). Psychometric theory. New York, NY: McGraw-Hill.

Sim, J., Mak B. and Jones, D. (2006): A Model of Customer Satisfaction and Retention for Hotels, Journal of Quality Assurance in Hospitality and Tourism, Vol. 7(3), pp.1-23

Southgate, C. Sharpley, R. (2002). Tourism Development and the Environment, in Sharpley, R. and Telfer, D. J. (eds), Tourism and Development: Concepts and issues, Channel View, Clevedon, UK.

Taleghani, M. (2010). Tourism as an Economic Development Tool. Journal of American Science, 6(11), 412-416.

Tourism Malaysia (2011). Tourism today. Malaysia: Tourism Malaysia, Ministry of Tourism.

United Nations (2007). Study on the role of tourism in socio-economic development.

World Tourism Organization (2011). UNWTO Tourism Highlights 2011 Edition.

World Travel and Tourism Council Data, (2013). Retrieved from http://knoema.com/WTTC2013/world-travel-and-tourism-council-data2013

Yuksel, F., Bramwell, B. and Yuksel, A. (1999). Stakeholder Interviews and Tourism Planning at Pamukkale, Turkey, Tourism Management, 20, 351-360. 